\title{
Oropharyngeal Polyp
}

National Cancer Institute

\section{Source}

National Cancer Institute. Oropharyngeal Polyp. NCI Thesaurus. Code C5988.

A benign exophytic growth that arises from the oropharynx. 